\title{
Impaired mitophagy activates mtROS/HIF-1 $\alpha$ interplay and increases cancer aggressiveness in gastric cancer cells under hypoxia
}

\author{
MASAAKI SHIDA $^{1}$, YOSHIHIKO KITAJIMA ${ }^{1,2}$, JUN NAKAMURA ${ }^{1}$, KAZUYOSHI YANAGIHARA $^{3}$, \\ KOICHI BABA ${ }^{1}$, KOTA WAKIYAMA ${ }^{1}$ and HIROKAZU NOSHIRO ${ }^{1}$ \\ ${ }^{1}$ Department of Surgery, Saga University Faculty of Medicine, Saga 849-8501; \\ ${ }^{2}$ Department of Surgery, NHO Higashisaga Hospital, Miyaki-Town, Miyaki-Gun, \\ Saga 849-0101; ${ }^{3}$ Division of Pathology, Research Center of Innovative Oncology, \\ National Cancer Center Hospital East, Kashiwa-Shi, Chiba 277-8577, Japan
}

Received November 26, 2015; Accepted December 18, 2015

DOI: $10.3892 /$ ijo.2016.3359

\begin{abstract}
Mitochondrial autophagy (mitophagy) is a selective form of autophagy and a critical step in excluding mitochondria damaged by stress, including hypoxia. This study aimed to determine whether the integrity of mitophagy affected production of the mitochondrial reactive oxygen species (mtROS), hypoxia inducible factor (HIF)-1 $\alpha$ expression and aggressive characteristics in GC cells under hypoxia. Three GC cell lines, 44As3, 58As9 and MKN45, were investigated in this study. HIF-1 $\alpha$ expression was induced in the three GC cell lines under hypoxia, with higher expression observed in 44As3 and 58As9 cells compared with MKN45 cells. Cell survival and invasion abilities under hypoxia were significantly stronger in 44As3 and 58As9 cells than MKN45 cells. Moreover, mtROS accumulated in a time-dependent manner in 44As3 and 58As9 cells, but not in MKN45 cells. ROS scavenger N-acetyl-L-
\end{abstract}

Correspondence to: Dr Yoshihiko Kitajima, Department of Surgery, Saga University Faculty of Medicine, 5-1-1 Nabeshima, Saga 849-8501, Japan

E-mail: kitajiy@hosp.go.jp

Abbreviations: GC, gastric cancer; HIF-1 $\alpha$, hypoxia-inducible factor-1 $\alpha$; PHDs, prolyl hydroxylases; ROS, reactive oxygen species; ETC, electron transport chain; mtROS, mitochondrial ROS; LC3, microtubule-associated protein 1 light chain 3; SQSTM1, sequestosome 1; BNIP3, BCL2/adenovirus E1 B19 kDa proteininteracting protein 3; NIX, Nip3-like protein X; FUNDC, FUN14 domain containing 1; DMOG, dimethyloxallylglycine; NAC, $\mathrm{N}$-acetyl-L-cysteine; CQ, chloroquine diphosphate; siRNA, small interfering RNA; RFP, red fluorescent protein; RT-qPCR, real-time quantitative reverse transcription polymerase chain reaction; MTS, 3-(4,5-dimethylthiazol-2-yl)-5-(3-carboxymethoxyphenyl)-2-(4sulfophenyl)-2H-tetrazolium; GLUT1, glucose transporter 1; PDK1, pyruvate dehydrogenase kinase 1 ; LDHA, lactate dehydrogenase A

Key words: mitophagy, HIF-1 $\alpha$, reactive oxygen species, gastric cancer, hypoxia, survival, invasion cysteine (NAC) treatment resulted in strong attenuation of HIF-1 $\alpha$ expression, whereas HIF-1 $\alpha$ knockdown increased ROS production in the three GC cell lines under hypoxia. These results suggested that the mtROS/HIF-1 $\alpha$ interplay affected the hypoxia-induced cancer aggressiveness. Assessment of mitophagy by LC3-I/II conversion, SQSTM1/p62 degradation and specific fluorescence markers demonstrated that hypoxiainduced mitophagy was observed only in MKN45 cells, while the process was impaired in the other two cell lines. Treatment with the autophagy inhibitor chloroquine conversely increased HIF-1 $\alpha$ expression, mtROS generation, cell survival and invasion in hypoxic MKN45 cells. The present study revealed a novel mechanism in which the integrity of mitophagy might determine cancer aggressiveness via $\mathrm{mtROS} / \mathrm{HIF}-1 \alpha$ interplay in GC cells under hypoxic conditions.

\section{Introduction}

Gastric cancer (GC) is the fourth most common malignancy in the world (1). To date, systemic chemotherapy in addition to surgery has improved the survival in some patients with advanced GC, but treatments for patients with far advanced or potentially aggressive GC often result in poor survival owing to metastases to distant organs $(2,3)$. At present, the underlying mechanisms that accelerate invasion or metastasis in GC are not well documented.

The hypoxic environment is substantial in solid tumors, where it accelerates their malignant behavior (4-8). Hypoxia inducible factor (HIF)- $1 \alpha$ is a transcription factor that is induced under hypoxic conditions and monitors the cellular response to oxygen levels in solid tumors $(9,10)$. Under normoxia, prolyl hydroxylases (PHDs) hydroxylate proline residues of HIF-1 $\alpha$ in a reaction that uses $\mathrm{O}_{2}$ as a substrate, and the modified HIF- $1 \alpha$ is subsequently degraded by the ubiquitin proteasome system. Under hypoxia, HIF-1 $\alpha$ protein is stabilized owing to the absence of $\mathrm{O}_{2}$ substrate and instead forms a heterodimer with the HIF-1 $\beta$ subunit (11-14). The HIF-1 complex then activates the transcription of hundreds of target genes and leads to adaptation to the hypoxic environment $(11,12)$. HIF-1 $\alpha$ 
has been reported to upregulate target genes related to energy metabolism, angiogenesis, cell proliferation or survival, invasion or metastasis, and drug resistance in human cancer cells (13-15). In GC, previous studies have also reported that HIF-1 $\alpha$ activation following extended hypoxia strongly correlates with an aggressive tumor phenotype and poor prognosis of patients (16-19). Therefore HIF-1 $\alpha$ is recognized as a central regulator of GC pathogenesis $(14,20)$.

Reactive oxygen species (ROS) such as superoxide are generated mainly through the electron transport chain (ETC) $(21,22)$. Hypoxia is known to stimulate the ROS production from mitochondrial complex III in the ETC (23). Lower levels of mitochondrial ROS (mtROS) play important roles as signaling molecules to adapt to stress and are required for normal cell homeostasis, while excessive quantities of mtROS directly damage proteins, lipids and nucleic acids, and lead to cell death (21). Previous reports have shown that HIF-1 $\alpha$ is also stabilized by mtROS, whereby mtROS inactivate PHDs by decreasing intracellular $\mathrm{Fe}^{2+}$ levels through oxidization to $\mathrm{Fe}^{3+}$ (24-27).

Macroautophagy (general autophagy) is a dynamic process through which cytosol and organelles are sequestered into a double-membrane vesicle called an autophagosome and delivered to the lysosome for breakdown and recycling during challenging conditions, such as nutrient depletion or hypoxia. The core process of general autophagy is mediated by autophagy-related (ATG) genes. The conversion of LC3-I to LC3-II and degradation of SQSTM1/p62 (referred as p62) are known to indicate the autophagy process (28-30). Mitochondrial autophagy, designated as mitophagy, is a selective form of autophagy in which mitochondria are degraded in autolysosomes $(31,32)$. Mitophagy represents a critical adaptive mechanism to maintain oxygen homeostasis and to eliminate old and/or damaged mitochondrion in response to certain stresses including hypoxia $(33,34)$. In addition to the core factors in the autophagy, previous studies have revealed that specific regulators such as BNIP3, NIX, Parkin, Pink1 and FUNDC1 are required for promoting mitophagy (31,34-36). Recently, emerging evidence has revealed that deregulation in key regulators of mitophagy is found in several cancers and suggested a possible implication in tumorigenesis (34). For instance, Parkin located at human chromosome 6q25-q26 is frequently deleted in bladder, lung, breast and ovarian cancers. These reports highlight the roles of mitophagy-related factors as potential tumor suppressors $(37,38)$. However, the mechanisms underlying deregulated mitophagy in tumorigenesis or cancer progression have not been elucidated.

In the present study, we first compared HIF-1 $\alpha$ expression level with mtROS production and cancer aggressiveness in three GC cell lines under hypoxic conditions. We evaluated whether the integrity of mitophagy affects mtROS production and HIF-1 $\alpha$ expression in these cells. This study presents a novel mechanism of cancer aggressiveness through activated mtROS/HIF- $1 \alpha$ interaction, which originated from impaired mitophagy, in GC cells under hypoxic conditions.

\section{Materials and methods}

Cell culture and exposure to hypoxia. Three human GC cell lines (44As3, 58As9 and MKN45) were used in this study. The 44As3 and 58As9 cell lines were kindly provided by
Dr K. Yanagihara (National Cancer Center Hospital East, Chiba, Japan); these two cell lines are scirrhous GC cell lines and have strong potential for inducing the formation of peritoneal metastasis in the orthotopic mouse model $(39,40)$. MKN45 cells were purchased from Cell Bank, RIKEN BioResource Center (Tsukuba, Japan), and these cells are non-scirrhous GC cells. All cells were cultured in RPMI-1640 medium (Sigma-Aldrich, St. Louis, MO, USA) supplemented with $10 \%$ heat-inactivated FBS and $100 \mu \mathrm{g} / \mathrm{ml}$ kanamycin (Meiji, Tokyo, Japan), and maintained under either normoxic conditions $\left(20 \% \mathrm{O}_{2}\right.$ and $5 \% \mathrm{CO}_{2}$ in air) or hypoxic conditions $\left(1 \% \mathrm{O}_{2}, 5 \% \mathrm{CO}_{2}\right.$ and $\left.94 \% \mathrm{~N}_{2}\right)$ in a hypoxic chamber (Astec, Fukuoka, Japan).

Reagents. DMOG (Sigma-Aldrich) was used as the inhibitor of PHDs, NAC (Wako, Osaka, Japan) was used as the ROS scavenger and CQ (Sigma-Aldrich) as the autophagy inhibitor. The reagents were dissolved in deionized water and used at the indicated concentration. The working concentrations were determined as DMOG at $1 \mathrm{mM}$ for $4 \mathrm{~h}, \mathrm{NAC}$ at $20 \mathrm{mM}$ for $4 \mathrm{~h}$ and $\mathrm{CQ}$ at $5 \mu \mathrm{M}$.

RNA interference for $H I F-1 \alpha$. The siRNA for the human HIF-1 $\alpha$ gene (SASI_Hs02_00332063) and the non-silencing siRNA control (Mission ${ }^{\circledR}$ siRNA Universal Negative Control) were purchased from Sigma-Aldrich. The siRNAs were transiently transfected into 44As3, 58As9 and MKN45 cells using a MicroPorator-mini (MP-100) (Digital Bio Technology, Seoul, Korea) in combination with the Neon ${ }^{\mathrm{TM}} 100-\mu 1$ kit (Thermo Scientific, Waltham, MA, USA) according to the manufacturer's instructions. The transfectants were cultured in complete medium and harvested on days 1-2 after transfection. The transfected cells were cultured in complete medium and harvested on days 1-3 for a westren blot analysis.

Western blot analysis. Whole cell lysates from cultured cells were prepared using a lysis buffer composed of $150 \mathrm{mM} \mathrm{NaCl}$, $50 \mathrm{mM}$ Tris- $\mathrm{HCl}(\mathrm{pH} 7.6), 0.5 \%$ Triton $\mathrm{X}-100$ containing a protease inhibitor cocktail mix (Roche Diagnostics GmbH, Mannheim, Germany) and $1 \mathrm{mM}$ PMSF (Sigma-Aldrich). Protein samples $(15 \mu \mathrm{g})$ were electrophoresed with NuPAGE $4-12 \%$ or $12 \%$ Bis-Tris gel (Invitrogen, Waltham, MA, USA) and were transferred onto polyvinylidene fluoride membranes using the Trans-Blot ${ }^{\circledR}$ Turbo $^{\mathrm{TM}}$ Transfer System (Bio-Rad, Hercules, CA, USA). After blocking with 5\% skim milk for $1 \mathrm{~h}$, the membranes were incubated with primary antibodies overnight at $4^{\circ} \mathrm{C}$. Following incubation with the corresponding secondary antibodies, the signals were developed using the Amersham $^{\mathrm{TM}}$ ECL Prime Western Blotting Detection Reagent (GE Healthcare, Buckinghamshire, UK).

Antibodies. The primary antibodies used in this study were mouse monoclonal anti-HIF-1 $\alpha$ antibody $(1: 1,000$, Becton-Dickinson Biosciences, NJ, USA), rabbit polyclonal anti-SQSTM1/p62 antibody (1:1,000, Cell Signaling, Danvers, MA, USA), rabbit monoclonal anti-LC3-I/II antibody (1:1,000, Cell Signaling), and mouse monoclonal anti- $\beta$-actin antibody (1:10,000, Sigma-Aldrich). Goat anti-rabbit IgG-HRP and goat anti-mouse IgG-HRP (Santa Cruz Biotechnology, Inc., Dallas, TX, USA) were used as secondary antibodies. 
Real-time quantitative reverse-transcription polymerase chain reaction ( $R T-q P C R)$. Total RNA was extracted from each cell line using an Isogen II (Nippon Gene, Osaka, Japan) according to the manufacturer's instructions. For each cell line, $1 \mu \mathrm{g}$ of RNA was converted into cDNA using a ReverTra Ace (Toyobo, Osaka, Japan); reverse transcription reaction kit. The cDNA was used as a template for the PCR. RT-qPCR was performed by means of the LightCycler ${ }^{\mathrm{TM}}$ instrument system using the Light-Cycler-FastStart DNA Master ${ }^{\mathrm{TM}}$ SYBR Green I kit (Roche Diagnostics GmbH). The primer sequences designed according to cDNA sequences by Ensemble and NCBI Primer-BLAST system were as follows: HIF- $1 \alpha$ sense 5'-CCTATGACCTGCTTGGTGCT-3' and antisense 5'-TAT CCAGGCTGTGTCGACTG-3' (175-bp product); and $\beta$-actin sense 5'-ACTCTTCCAGCCTTCCTTCC-3' and antisense 5'-GACAGCACTGTCTTGGCGTA-3' (120-bp product). After performing a denaturation step at $95^{\circ} \mathrm{C}$ for $3 \mathrm{~min}, \mathrm{PCR}$ amplification was conducted with 50 cycles of $15 \mathrm{sec}$ of denaturation at $95^{\circ} \mathrm{C}, 5 \mathrm{sec}$ of annealing at $60^{\circ} \mathrm{C}$ and $10 \mathrm{sec}$ of extension at $72^{\circ} \mathrm{C}$. A melting curve analysis was used to control for the specificity of the amplification products. The quantitative values were normalized by the $\beta$-actin expression level, which was used as an internal control. All experiments were performed in triplicate and the mean values were calculated. The experiments were independently repeated three times.

Cell survival assay. Cell survival ability was assessed with MTS assay using the CellTiter $96{ }^{\circledR}$ AQueous One Solution Cell Proliferation Assay kit (Promega Corp., Madison, WI, USA). In brief, $1.5 \times 10^{3}$ cells per well were seeded in triplicate in 96-well plates and incubated under hypoxic conditions. Numbers of viable cells were assessed by measuring the optical density at $490 \mathrm{~nm}$ using a plate reader (iMark Microplate Reader, Bio-Rad) in triplicate at $0,12,24$ and $48 \mathrm{~h}$ under hypoxia. The mean values were estimated and the relative proliferation values are presented as the ratio to $0 \mathrm{~h}$. The experiments were independently repeated three times.

Cell invasion assay. In vitro invasion assays were performed using the Falcon ${ }^{\circledR}$ Permeable Support for 24-well plates with transparent PET membrane with $8.0-\mu \mathrm{m}$ pores (Corning, NY, USA). Briefly, invasion chambers were coated with $50 \mu \mathrm{l}$ $(1 \mathrm{mg} / \mathrm{ml})$ of Corning ${ }^{\circledR}$ Matrigel ${ }^{\circledR}$ Basement Membrane Matrix Phenol Red-Free (Corning) in cold RPMI-1640 medium and dried overnight. Suspensions of $1 \times 10^{5}$ cells in $200 \mu \mathrm{l}$ of complete RPMI-1640 medium were placed in the upper compartments of the chamber, while the lower compartments were filled with $800 \mu \mathrm{l}$ of conditioned medium obtained from MRC5 fibroblasts. The culture units were incubated for $24 \mathrm{~h}$ at $37^{\circ} \mathrm{C}$ under normoxic $\left(20 \% \mathrm{O}_{2}\right)$ and hypoxic $\left(1 \% \mathrm{O}_{2}\right)$ condition. Thereafter the non-invasive cells on upper surface of the filters were then gently removed using a cotton swab moistened with medium. Viable invaded cells that had infiltrated onto the lower surface of the filter were fixed with $70 \%$ ethanol and the nuclei were stained with Mayer's hematoxylin (Muto Pure Chemicals, Tokyo, Japan). Number of the invaded cells was counted under a light microscope. The experiments were performed in triplicate and independently repeated at least three times.
Quantitative analysis of intracellular ROS. Intracellular ROS levels were estimated using the Total ROS Detection kit (Enzo Life Sciences Inc., Farmingdale, NY, USA) according to the manufacturer's instructions. In brief, cells at 50-60\% confluence were incubated for 0-48 $\mathrm{h}$ under normoxic and hypoxic conditions. Cells were harvested using $0.05 \%$ trypsin-EDTA (Wako) and stained with ROS detection dye for $30 \mathrm{~min}$ at $37^{\circ} \mathrm{C}$ in the dark. ROS were measured on a FACSCalibur (BectonDickinson, San Jose, CA, USA), and the intensity levels were analyzed by Cell Quest softwear program. The experiments were performed in triplicate and independently repeated at least three times. The mean fluorescence of ROS production was determined automatically and presented as the GEO mean.

Immunofluorescence. Cells were immunolabeled with the antibodies and reagents according to the manufacturer's instructions. In brief, the medium was removed and cells were washed at least twice. For staining of mitochondrion and lysosomes, Mitotracker ${ }^{\circledR}$ Green FM (Thermo Scientific), mitochondrion selective probes, and Lysotracker ${ }^{\circledR}$ Red DND-99 (Thermo Scientific), lysosome selective probes, were added to living cells at the final concentrations of 0.1 and $0.025 \mu \mathrm{M}$, respectively. Mitophagy was assessed by the colocalization of Mitotracker and Lysotracker, as described elsewhere (42).

To evaluate mtROS, MitoSOX ${ }^{\circledR}$ Red (Thermo Scientific), a mitochondrial superoxide indicator, was added to living cells at $5 \mu \mathrm{M}$. To monitor autophagy, $5 \mu \mathrm{l}$ of Premo ${ }^{\mathrm{TM}}$ Autophagy Sensor LC3B-RFP (Thermo Scientific) was added to $1 \times 10^{4}$ cells in media and incubated for $24 \mathrm{~h}$. LC3B (G120A)-RFP was used for the positive control according to the manufacturer's instructions. Cell nuclei were counterstained by $1 \mu \mathrm{M}$ Hoechest 33342 (Thermo Scientific). MitoSOX-Red or LC3B-RFP positive cells were visualized under an EVOS ${ }^{\circledR}$ FLoid $^{\circledR}$ Cell Imaging Station (Thermo Scientific) and the numbers of positive cell were counted.

Statistical analysis. Statistical analysis was performed using the computer software program SPSS 22 for Windows (SPSS Inc, Chicago, IL, USA). Comparisons between two groups were made using Student's t-test and the Mann-Whitney U test. P-values of $<0.05$ were considered to be statistically significant.

\section{Results}

HIF-1a protein levels correlate with cell survival and invasion activities in GC cell lines under hypoxia. We first examined the relationship between HIF-1 $\alpha$ expression levels with cell survival and invasion activities among three GC cell lines, 44As3, 58As9 and MKN45, under hypoxia. HIF-1 $\alpha$ was induced in all cell lines at 12-48 h under hypoxic conditions. However, the HIF-1 $\alpha$ protein levels varied among the cell lines (Fig. 1A). Expression of HIF-1 $\alpha$ protein, which peaked at $12-24 \mathrm{~h}$ of hypoxia, was more strongly induced in 44As3 and 58As9 cells in comparison to MKN45 cells. Real-time quantitative reverse-transcription polymerase chain reaction (RT-qPCR) showed that HIF-1 $\alpha$ mRNA was expressed in all three cell lines under normoxia as well as hypoxia conditions (Fig. 1B). The strongest mRNA expression was observed in MKN45 cells among the cell lines. 
A

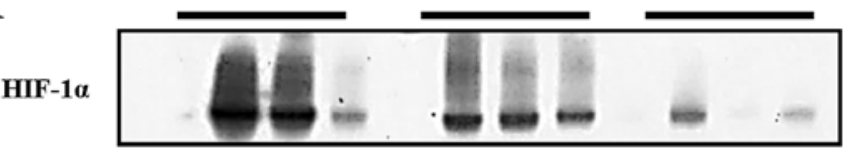

$\beta$-Actin

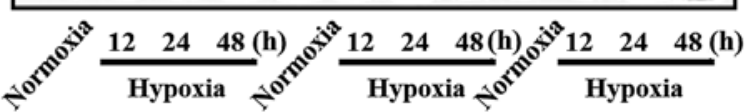

$\mathrm{C}$

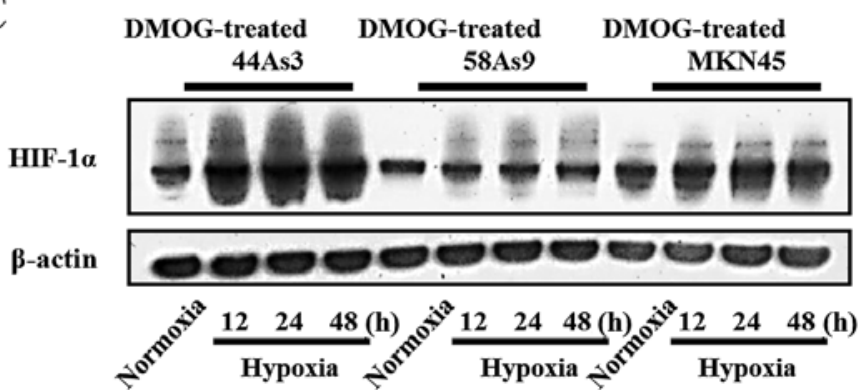

B $\left(\times 10^{-3}\right)$

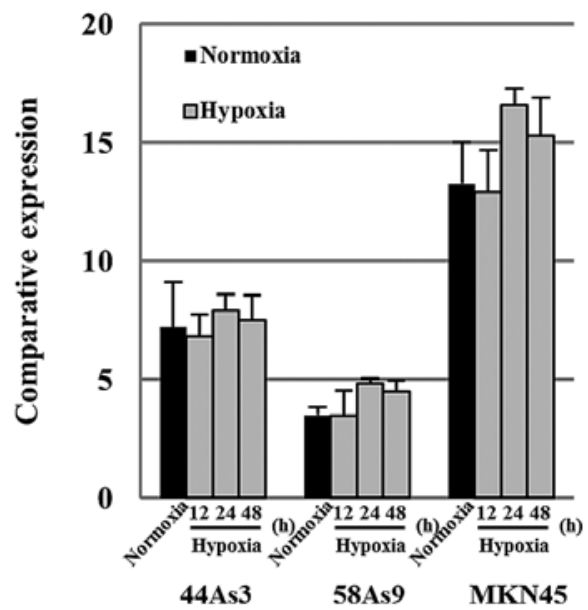

$\mathrm{E}$

$\mathrm{D}$
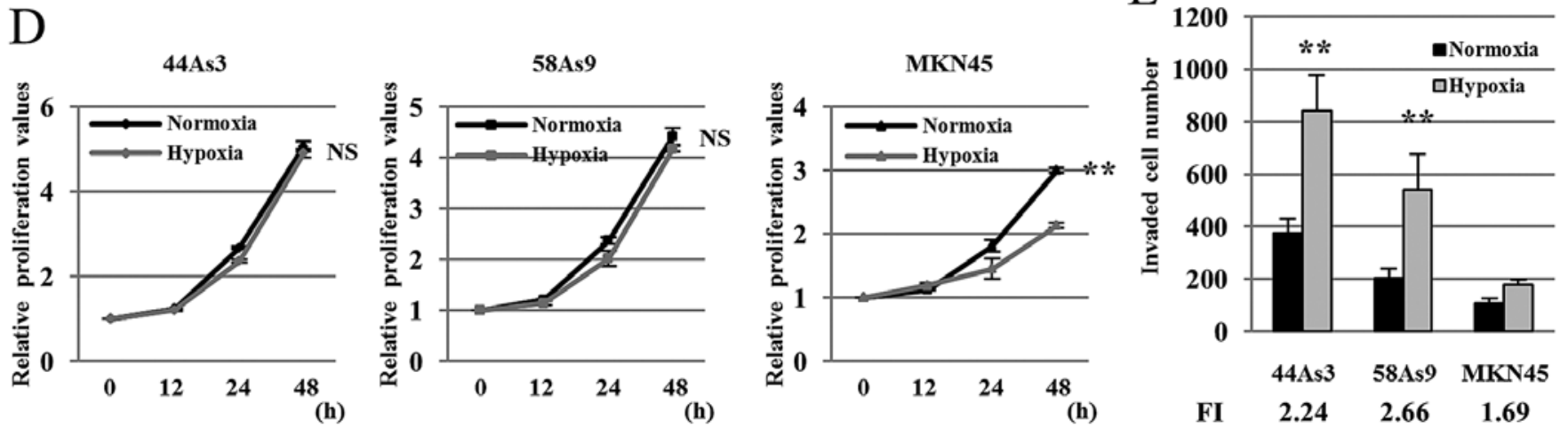

Figure 1. HIF-1 $\alpha$ expression levels, cell survival and invasion activity in three GC cell lines under hypoxia. (A) Western blot analysis of HIF-1 $\alpha$ in three GC cell lines under hypoxia for $12-48 \mathrm{~h}$. $\beta$-actin used as a control was equally expressed in all cell lines. (B) RT-qPCR analysis of HIF-1 $\alpha$ mRNA in three GC cell lines under hypoxia for 12-48 h. Expression levels of HIF- $1 \alpha$ mRNA in 44As3, 58As9 and MKN45 cells were normalized by those of $\beta$-actin mRNA. (C) Western blot analysis of HIF-1 $\alpha$ in three GC cell lines treated with the PHD inhibitor DMOG. (D) Cell proliferation of three GC cell lines under normoxia or hypoxia for 12-48 h. (E) Invasion abilities of three GC cell lines under normoxia or hypoxia were analyzed by Matrigel in vitro invasion assay. Graph shows mean number of invaded cells after $24 \mathrm{~h}$ of normoxia or hypoxia. The fold induction (FI) was estimated as the invasion ratio of hypoxia/normoxia. All experiments were performed in triplicate, and data are presented as mean $\pm \mathrm{SD}$. NS, not significant; ${ }^{*} \mathrm{P} \leq 0.05,{ }^{* * *} \mathrm{P} \leq 0.01$.

HIF-1 $\alpha$ protein expression was further analyzed in three GC cell lines with treatment of the PHD inhibitor dimethyloxallylglycine (DMOG). HIF-1 $\alpha$ protein expression was increased by DMOG treatment in all three GC cell lines under both normoxia and hypoxia (Fig. 1C). Next, cell survival was analyzed by MTS assay. Cell viability of 44As3 and 58As9 cells was not affected by hypoxic stimulation. On the other hand, cell survival of MKN45 cells was suppressed for 24-48 h under hypoxia in comparison to normoxia, and the survival rate at $48 \mathrm{~h}$ was significantly lower under hypoxia than normoxia (Fig. 1D). We also analyzed cell invasion activities in the three GC cell lines after $24 \mathrm{~h}$ of normoxia and hypoxia. Hypoxiainduced invasion was evaluated as fold induction (FI), which was estimated as the ratio of invaded cell numbers under hypoxia compared with those of normoxia. Results showed that 44As3 and 58As9 cells exhibited higher FI than MKN45 cells, both overall and under hypoxic condition (Fig. 1E).

Mitochondrial ROS specifically accumulates in GC cell lines with aggressive characteristics. We next evaluated the level of intracellular ROS in three GC cell lines under hypoxia. As shown in Fig. 2A, ROS production was increased in 44As3 and 58As9 cells, but not in MKN45 cells under hypoxia in a time-dependent manner. ROS levels at 48 -h hypoxia were significantly higher in 44As3 and 58As9 cells compared with MKN45 cells. Mitochondrial ROS (mtROS) production in the three cell lines was next investigated using MitoSOX-Red staining, a specific fluorescent marker (Fig. 2B). Under normoxia conditions, we did not detect any mtROS determined by MitoSOX-Red staining in all three cell lines. However, MitoSOX-positive cells were observed in 44As3 and 58As9 cells, but not in MKN45 cells, after 48-h hypoxia. Merged staining with the Mitotracker mitochondria marker confirmed ROS production in the mitochondria of hypoxic 44As3 and 58As9 cells (Fig. 2B). The rate of positive MitoSOX-stained cells at $48 \mathrm{~h}$ was significantly higher under hypoxia than normoxia conditions in these two cell lines. A lower frequency of MitoSOX staining was observed in MKN45 cells under both normoxia and hypoxia (Fig. 2C).

Assessment of the interplay between ROS and HIF-1 $\alpha$ in three GC cell lines under hypoxia. To investigate the ROS/HIF-1 $\alpha$ 

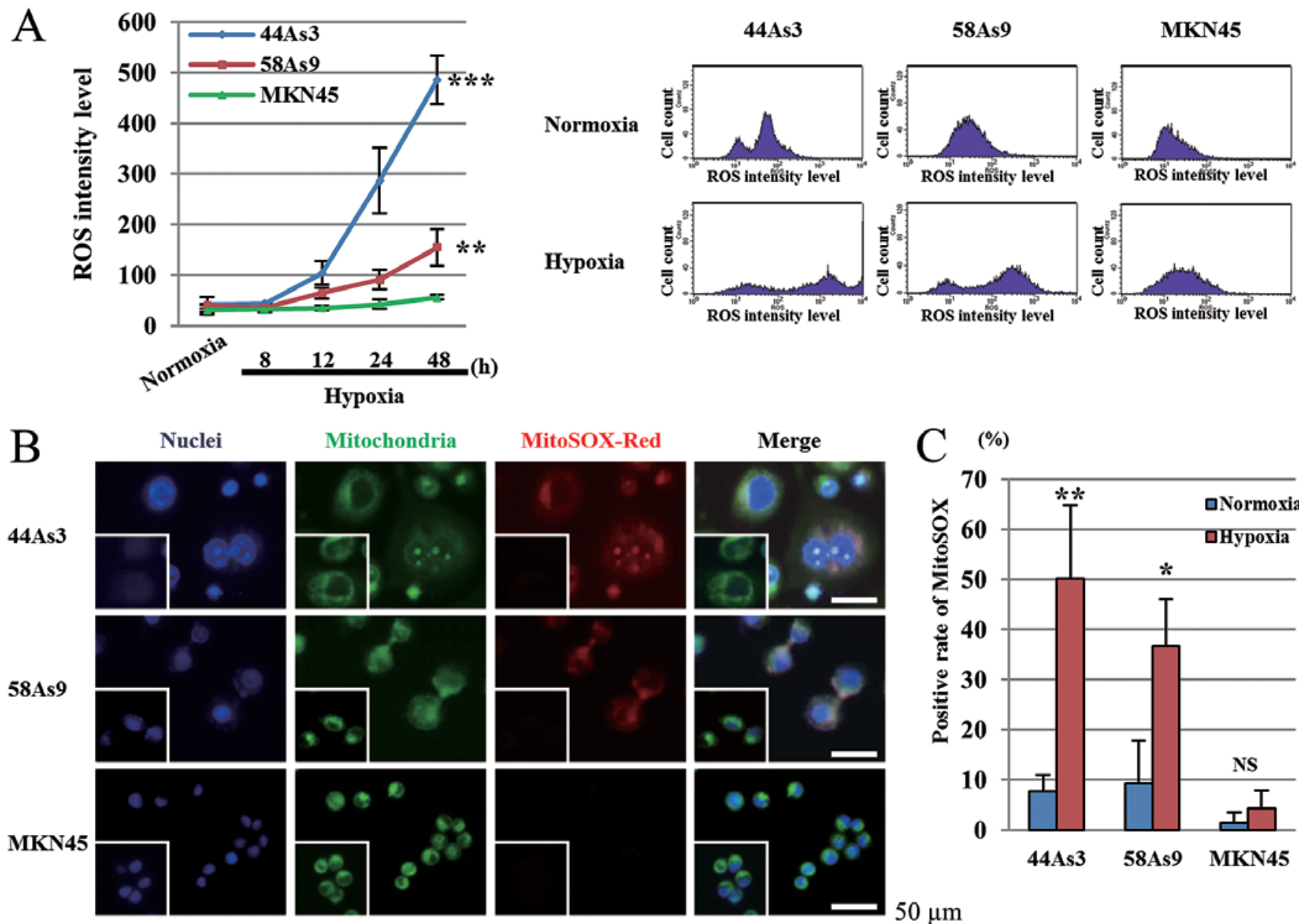

Figure 2. Assessment of mtROS production in three GC cell lines. (A) ROS intensity level of the three GC cell lines under hypoxia conditions at indicated time-points. In the right panel, the peak fraction of ROS shifted to the right in 44As3 and 58As9 cells after $48 \mathrm{~h}$ of hypoxia in comparison to normoxia, but not in MKN45 cells. (B) Fluorescence microscopy analysis for localization of mtROS production at $48 \mathrm{~h}$ of hypoxia. The insert in each panel shows control experiments under normoxia. Nuclei were stained with Hoechst 33342 (blue), mitochondria were stained with Mitotracker (green) and mtROS was stained with MitoSOX-Red (red). Positive mtROS staining was observed in hypoxic 44As3 and 58As9 cells. In the merged panels, the light yellow areas show co-localization of Mitotracker and MitoSOX-Red in 44As3 and 58As9 cells. Scale bar, $50 \mu \mathrm{m}$. (C) Mean positive MitoSox-Red cell numbers in three GC cell lines under hypoxia or normoxia. All experiments were performed in triplicate, and data are presented as mean $\pm \mathrm{SD}$. NS, not significant; ${ }^{*} \mathrm{P} \leq 0.05 ;{ }^{* *} \mathrm{P} \leq 0.01$; ${ }^{* * * *} \mathrm{P} \leq 0.001$

interplay under hypoxic conditions, we first analyzed HIF-1 $\alpha$ expression with or without the treatment of the antioxidant reagent NAC. As shown in Fig. 3A, NAC treatment strongly decreased ROS production in all three cell lines under hypoxia for 12-48 h. There were significant differences in ROS levels at 48-h hypoxia between NAC treatment and no treatment in all three GC cells. Furthermore, NAC treatment strongly decreased HIF-1 $\alpha$ expression in all cell lines under hypoxia for 12-48 h (Fig. 3B).

We next evaluated ROS production in the three GC cell lines knocked down for HIF-1 $\alpha$ by siRNA (KD) compared with negative control siRNA (NC). Western blot analysis confirmed that HIF-1 $\alpha$ expression was strongly knocked down in all three cells lines transfected with HIF-1 $\alpha$ siRNA under hypoxia (Fig. 3C). ROS production was more strongly elevated in a time-dependent manner in each cell line knocked down for HIF-1 $\alpha$ compared with the corresponding negative control cells at 12-48-h hypoxia (Fig. 3D). There were significant differences in ROS levels at 48-h hypoxia between the HIF-1 $\alpha$ knockdown cell lines and negative controls.
Assessment of general autophagy in three GC cell lines. We next evaluated autophagy in three GC cell lines under hypoxic conditions. The conversion of LC3-I to LC3-II as well as the degradation of p62 was investigated by western blot analysis (Fig. 4A). From 8 to $48 \mathrm{~h}$ under hypoxia, the expression patterns of LC3-I/II and p62 were not altered in 44As3 and 58As9 cells. On the other hand, in MKN45 cells, the LC3-II isoform was increased under hypoxia in a time-dependent manner, resulting in a decreased LC3-I/II ratio. Moreover, p62 expression disappeared in these cells from $12 \mathrm{~h}$ of hypoxia (Fig. 4A). Autophagy was also analyzed by fluorescence microscopy of LC3B-RFP (Fig. 4B). LC3B-RFP was not detected in any of the three cell lines under normoxia (data not shown). Under $48 \mathrm{~h}$ of hypoxia, LC3B-RFP positive cells were observed in MKN45 cells but not in 44As3 and 58As9 cells (Fig. 4B). Furthermore, we observed co-localization of Mitotracker and LC3B-RFP in hypoxic MKN45 cells. The positive rate of LC3B-RFP was significantly higher under hypoxia conditions than in normoxia in MKN45 cells, while a lower rate was observed in 44As 3 and 58As9 cells under both conditions (Fig. 4C). 
A

$44 \mathrm{As} 3$

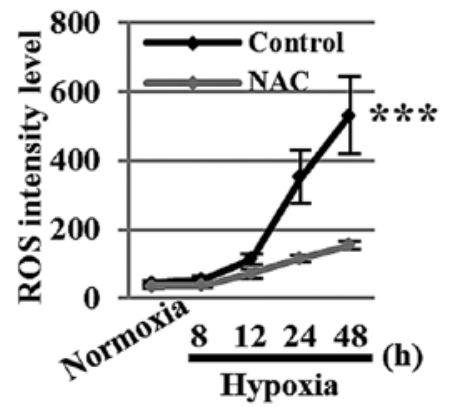

B

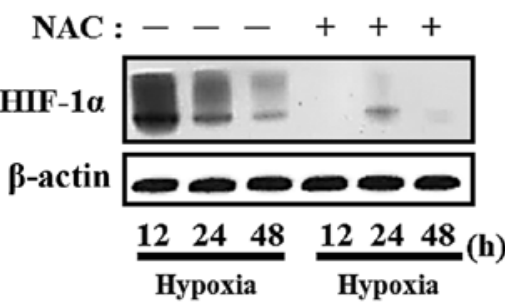

$\mathcal{C}$

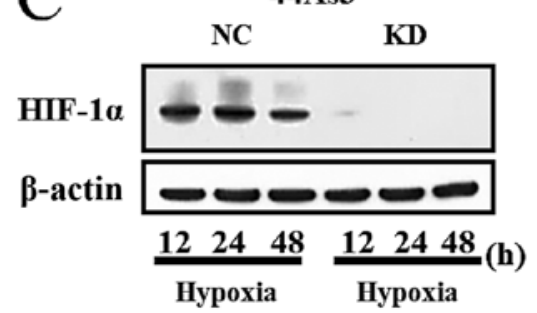

58As9

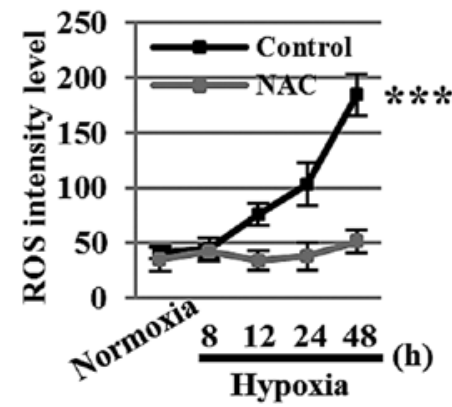

58As9

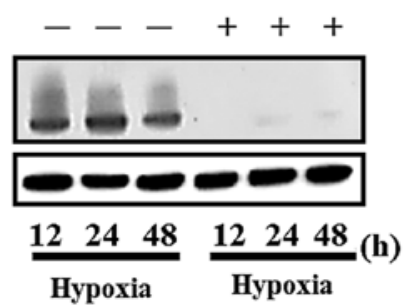

58As9

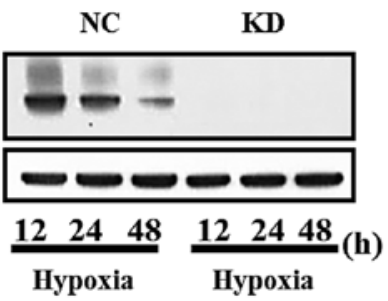

MKN45

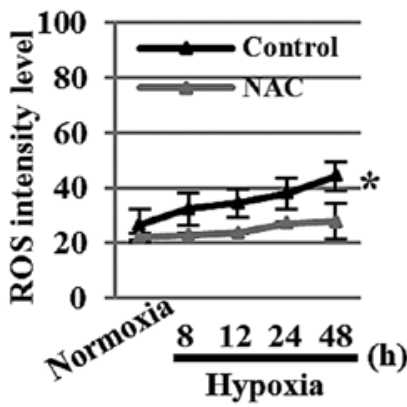

MKN45

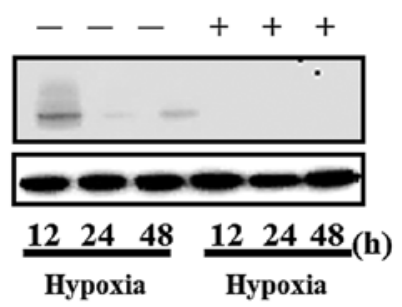

MKN45

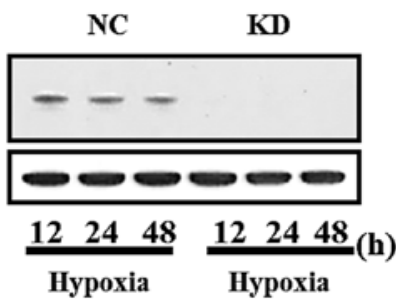

$\mathrm{D}$

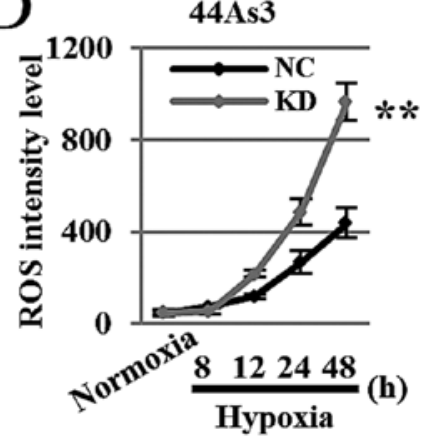

58As9

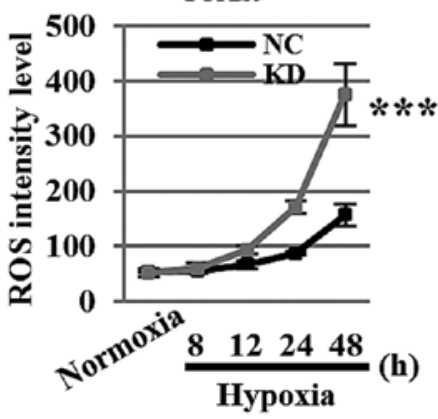

MKN45

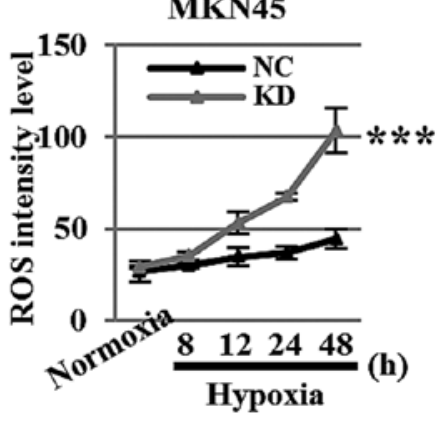

Figure 3. Assessment of ROS/HIF-1 $\alpha$ interplay in three GC cell lines under hypoxia. (A and B) ROS scavenger NAC inhibits HIF-1 $\alpha$ expression under hypoxia. (A) Intracellular ROS level was assessed in three GC cell lines for 8-48 h under hypoxia with or without NAC treatment. (B) HIF-1 $\alpha$ expression was assessed from 12-48 h of hypoxia with (+) or without (-) NAC treatment in three GC cell lines. $\beta$-actin used as control was equally expressed in three cell lines. MillQ was used as control. (C and D) Effect of knockdown of HIF-1 $\alpha$ expression on ROS generation in three GC cell lines. (C) Western blot analysis showed abolished HIF-1 $\alpha$ expression in cells knocked down for HIF-1 $\alpha$ (KD) compared with negative control (NC) in hypoxia and normoxia conditions. $\beta$-actin was equally expressed in all cells. (D) ROS intensity levels were determined in each HIF-1 $\alpha$ KD cell line and the corresponding NC cells. NC, negative control; KD, HIF-1 $\alpha$ knockdown. All experiments were performed in triplicate, and data are presented as mean $\pm \mathrm{SD}$. ${ }^{*} \mathrm{P} \leq 0.05 ;{ }^{* *} \mathrm{P} \leq 0.01 ;{ }^{* * *} \mathrm{P} \leq 0.001$.

Assessment of mitophagy in three GC cell lines. To evaluate the hypoxic induction of mitophagy, we analyzed the co-localization of the Mitotracker mitochondrial marker and Lysotracker lysosome marker in the three GC cell lines (Fig. 5A). Mitotracker-positive cells were observed in all three cell lines under both normoxia and hypoxia conditions. In contrast, lysosomes were more strongly stained by Lysotracker in MKN45 cells under hypoxia than normoxia. The intensity of lysosomal staining did not differ between the two conditions in 44As 3 and 58As9 cells. The merged image shows the co-localization of both markers in MKN45 cells (Fig. 5A). The positive rate of co-localized markers was significantly higher under hypoxia than normoxia in MKN45 cells, whereas there was no significant difference between the two conditions in 44As3 and 58As9 cells (Fig. 5B).

Inhibition of mitophagy increased malignant characteristics in MKN45 cells under hypoxia. We finally addressed whether inhibition of mitophagy by the autophagy inhibitor chloroquine diphosphate (CQ) affects ROS production, HIF-1 $\alpha$ 


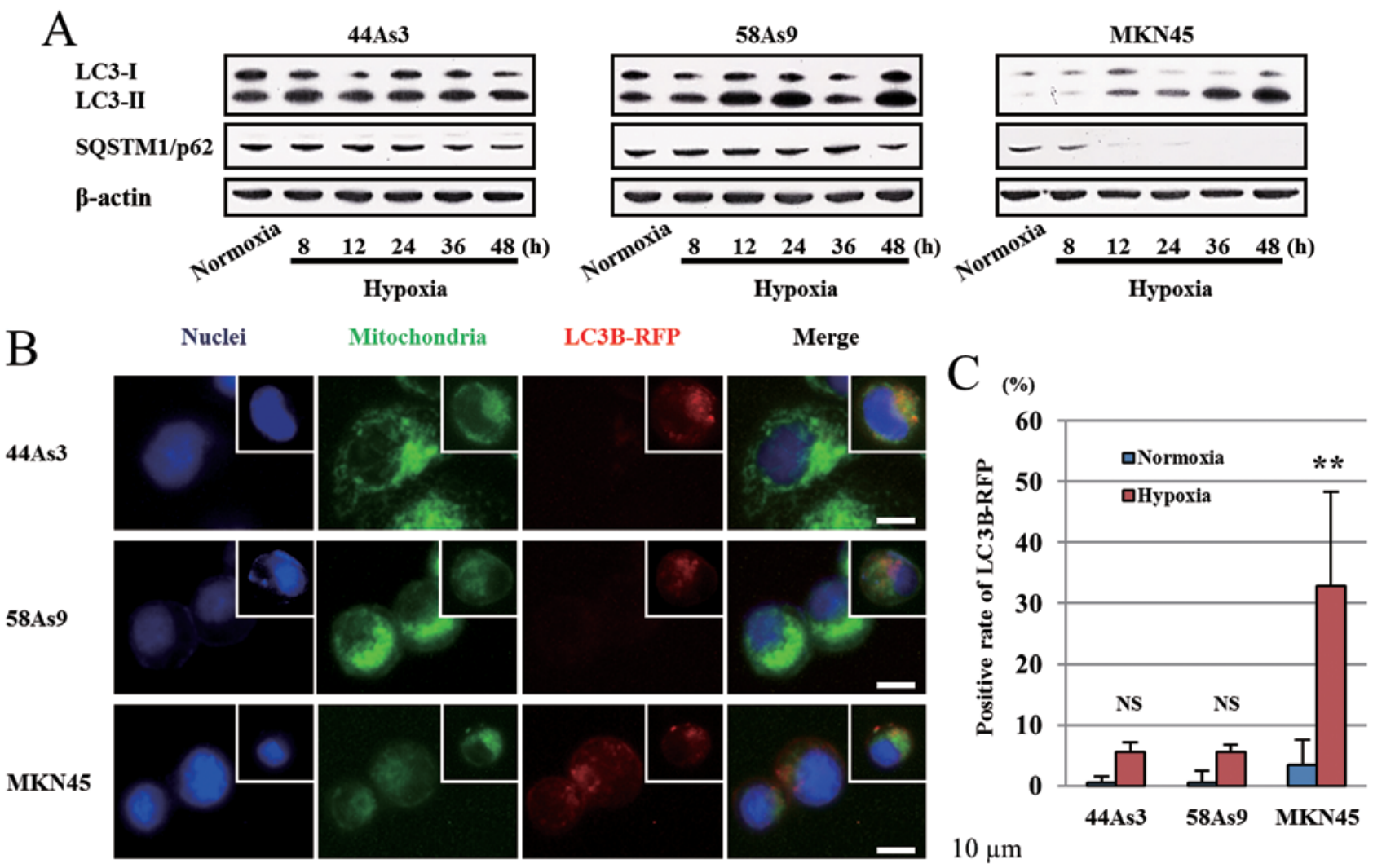

Figure 4. Hypoxia-induced mitophagy was impaired in 58As9 and 44As3 cells. (A) Western blot analysis of LC3-I/II and p62 was performed in three GC cell lines under hypoxia for 8-48 h. $\beta$-actin used as control was equally expressed in all cell lines. (B) Immunofluorescence analysis of three GC cell lines at $48 \mathrm{~h}$ of hypoxia. Nuclei were stained with Hoechst 33342 (blue), mitochondria were stained with Mitotracker (green) and cells undergoing autophagy were stained by LC3B-RFP (red). Positive controls are shown in the right upper insert. Scale bar, $10 \mu \mathrm{m}$. (C) Positive rate of LC3B-RFP was estimated as the ratio of LC3B-RFP positive cell numbers to total cell numbers. All experiments were performed in triplicate, and data are presented as mean \pm SD. NS, not significant; ${ }^{* *} \mathrm{P} \leq 0.01$.

A

44As3

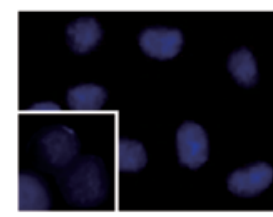

Nuclei
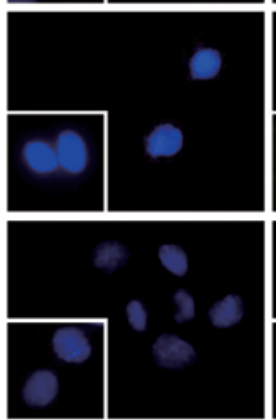

Mitotchondria
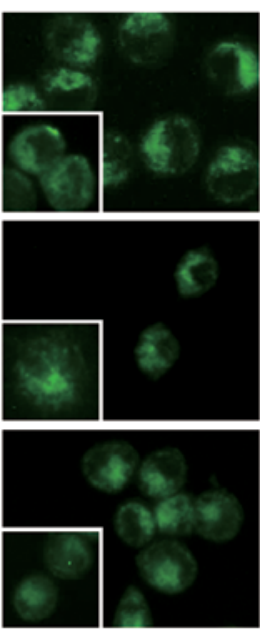

Lysosome
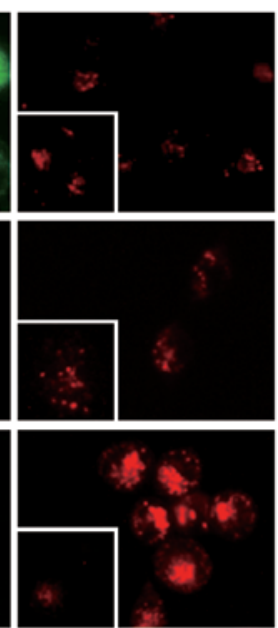

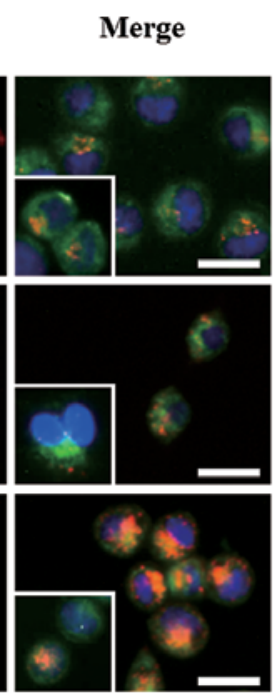

B

(\%)

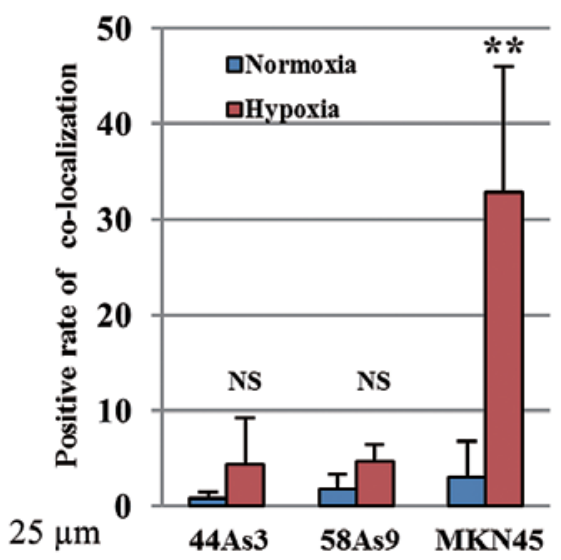

Figure 5. Autolysosome formation in mitochondria of hypoxic MKN45 cells. (A) Immunofluorescence analysis of formation of autolysosomes at $48 \mathrm{~h}$ of hypoxia. Nuclei were stained with Hoechst 33342 (blue), mitochondria were stained with Mitotracker (green) and lysosomes were stained with Lysotracker (red). The merged panels show co-localization of Mitotracker and Lysotracker staining in orange, which indicate positive mitophagy. The inserts show control experiments under normoxic conditions. (B) Positive rate of co-localized marker was estimated as the ratio of co-localized marker positive cell numbers to total cell numbers. All experiments were performed in triplicate, and data are presented as mean \pm SD. NS, not significant; ${ }^{* *} \mathrm{P} \leq 0.01$.

expression, cell survival and invasion in hypoxic GC cell lines (Fig. 6). Western blot analysis showed that the expression patterns of LC3-I/II and p62 did not differ between control and CQ treatment in 44As3 and 58As9 cells from 12-48 h of hypoxia. On the contrary, while we observed a decreased LC3-I/II ratio and p62 degradation in hypoxic control MKN45 


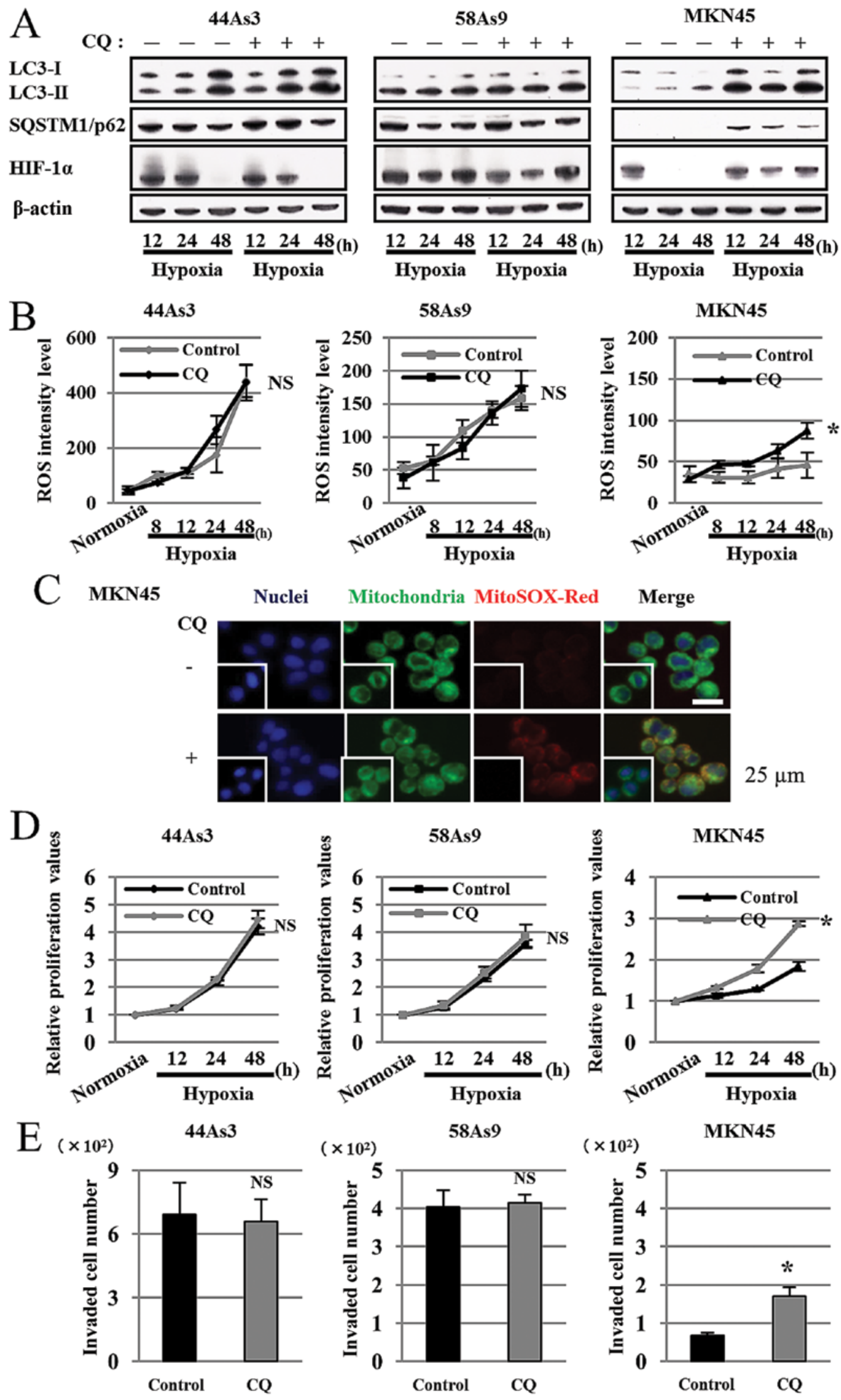

Figure 6. Impairment of mitophagy by chloroquine diphosphate (CQ) treatment activates mtROS/HIF-1 $\alpha$ interplay and increases cancer aggressiveness in MKN45 cells under hypoxia. (A) Inhibition of autophagy with CQ treatment. Three GC cell lines were treated with (+) or without (-) $5 \mu \mathrm{M} \mathrm{CQ}$, and LC3-I/II, p62 and HIF-1 $\alpha$ expressions were analyzed at $12-48 \mathrm{~h}$ under hypoxia. $\beta$-actin used as control was equally expressed in all cells. (B) ROS level was assessed in three cell lines with or without CQ treatment under 8-48 h of hypoxia. (C) Immunofluorescence to assess mtROS production in hypoxic MKN45 cells with (+) or without (-) CQ treatment. Nuclei were stained with Hoechst 33342 (blue), mitochondria were stained with Mitotracker (green) and mtROS were stained with MitoSOX-Red (red). The inserts show control cells under normoxia. (D) MTS assay in three cell lines with or without CQ treatment under hypoxic conditions for 12-48 h. (E) Invasion abilities of three cell lines with or without CQ treatment at $24 \mathrm{~h}$ under hypoxia. CQ, chloroquine diphosphate. Control, MillQ. All experiments were performed in triplicate, and data are presented as mean \pm SD. NS, not significant; ${ }^{P} \leq 0.05$. 

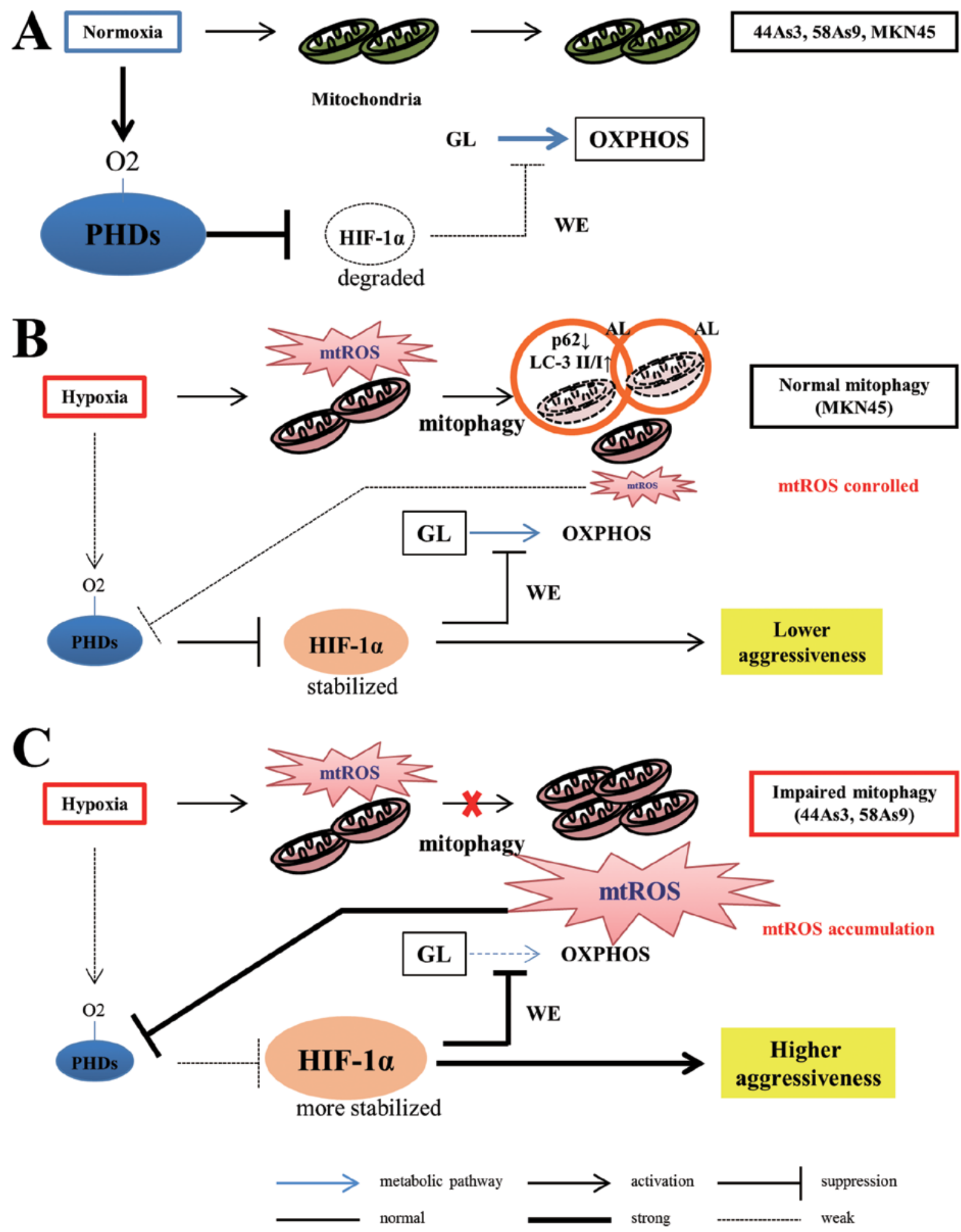

Figure 7. Schematic representation of cancer aggressiveness, which is increased by the activated mtROS/HIF-1 $\alpha$ interplay originating from impaired mitophagy in GC cells under hypoxia. (A) Under normoxic conditions, HIF-1 $\alpha$ is degraded by activated PHDs in GC cells. (B) Under hypoxia, HIF-1 $\alpha$ is stabilized owing to reduced PHDs activity. The mitochondria damaged by mtROS are excluded via mitophagy in MKN45 cells, and mtROS production is controlled at a low level. (C) Mitophagy is impaired in 44As3 and 58As9 cells under hypoxia and results in the accumulation of mtROS. The increased mtROS inhibits the activity of PHDs and further enhances HIF-1 $\alpha$ stability, leading to acceleration of cancer aggressiveness. The induced HIF-1 $\alpha$ conversely controls the increased mtROS level via activating the Warburg effect. AL, autolysosome; GL, glycolysis; OXPHOS, oxidative phosphorylation; WE, Warburg effect.

cells, these findings were not observed in hypoxic MKN45 cells treated with CQ (Fig. 6A). We also evaluated HIF-1 $\alpha$ expression in the three cell lines under hypoxia with or without CQ treatment. HIF-1 $\alpha$ expression was not affected in 44As3 and 58As9 cells with CQ treatment; however, the expression was restored in MKN45 cells with CQ treatment under 24-48 $\mathrm{h}$ of hypoxia (Fig. 6A). FACS analysis showed that ROS levels did not differ between control and CQ-treated hypoxic 
44As3 and 58As9 cells. However, ROS level was elevated in MKN45 cells with CQ treatment for 8-48 h under hypoxia in comparison to control cells. There was a significant difference in ROS levels at 48-h hypoxia between the treatments (Fig. 6B). Immunofluorescence using both Mitotracker and MitoSOX-Red confirmed ROS production in mitochondria of CQ-treated (+) but not the untreated (-) MKN45 cells under hypoxia (Fig. 6C). CQ treatment did not affect cell proliferation of 44As3 or 58As9 cells; however, CQ treatment increased cell survival in MKN45 cells for 12-48 h under hypoxia. There was a significant difference at 48-h hypoxia between the treatments (Fig. 6D). CQ treatment did not affect cell invasion of 44As3 and 58As9 cells. However, cell invasion was significantly higher in MKN45 cells with CQ treatment than those with control treatment at $24 \mathrm{~h}$ of hypoxia (Fig. 6E).

\section{Discussion}

We previously analyzed HIF-1 $\alpha$ expression in an immunohistochemical study of $91 \mathrm{GC}$ tissues and found positive nuclear staining of HIF-1 $\alpha$ in 87 of 91 (95.6\%) cases, suggesting that hypoxic environments frequently exist in GC tissues. We also further revealed that HIF-1 $\alpha$ expression level is important to determine aggressive tumor characteristics such as vessel invasion, chemoresistance and poor prognosis of patients (19). However, the precise correlation between HIF-1 $\alpha$ expression level and cancer aggressiveness using human cancer cell lines has not been elucidated. Therefore, in the present study, we investigated the correlation between HIF-1 $\alpha$ expression level and cancer aggressiveness using three GC cell lines under hypoxia.

We found that higher levels of HIF-1 $\alpha$ expression were induced by hypoxia in 44As3 and 58As9 cells compared with MKN45 cells. In vitro cell survival and invasion analysis also demonstrated that these abilities under hypoxia were stronger in the 44As3 and 58As9 cells in comparison to MKN45 cells. These results suggested a positive correlation between HIF-1 $\alpha$ expression level and hypoxia-induced aggressiveness among three GC cell lines. Notably, RT-qPCR analysis indicated that HIF- $1 \alpha$ mRNA levels did not reflect HIF-1 $\alpha$ protein levels in the GC cell lines. However, treatment with the PHDs inhibitor DMOG strongly restored HIF-1 $\alpha$ protein expression in three GC cell lines under both normoxia and hypoxia. The results suggest that HIF-1 $\alpha$ expression levels in the GC cell lines under these conditions depend on the PHDs activity, which determines the HIF-1 $\alpha$ protein stability. Previous studies reported that intracellular ROS increased HIF-1 $\alpha$ stability via PHDs inhibition (24-27) therefore we next compared mtROS levels among the three GC cell lines under hypoxia conditions. FACS analysis showed time-dependent accumulation of intracellular ROS in 44As3 and 58As9 cells, but not in MKN45 cells under hypoxia. Moreover, immunofluorescence confirmed the hypoxia-dependent accumulation of mtROS in 44As3 and 58As9 cells. These results indicated that the PHD activity in 44As3 and 58As 9 cells might be more strongly inhibited owing to the increased mtROS than that in MKN45 cells. Reduced degradation of HIF-1 $\alpha$ by the ubiquitin proteasome system might subsequently occur in 44As3 and 58As9 cells compared with MKN45 cells under hypoxic conditions. In contrast, NAC treatment strongly decreased
HIF-1 $\alpha$ expression in the three GC cell lines under hypoxia. These results indicated that re-activation of PHDs might be conversely promoted by ROS scavenging and increased HIF-1 $\alpha$ degradation in the three GC cell lines under hypoxia. Taken together, ROS-dependent inactivation of PHDs may determine HIF-1 $\alpha$ stabilization under hypoxic conditions. On the contrary, HIF-1 $\alpha$ knockdown increased ROS production in the three GC cell lines under hypoxic conditions. Previous studies reported that HIF-1 $\alpha$ controls ROS production under hypoxia through conversion of energy metabolism from oxidative phosphorylation to glycolysis, which is referred to as the Warburg effect. This metabolic change enables cancer cells to decrease $\mathrm{O}_{2}$ consumption in oxidative phosphorylation, leading to reduced ROS production. Furthermore, HIF-1 $\alpha$ is known to play a central role in the Warburg effect by upregulating target genes such as GLUT1, glycolytic enzymes, PDK1 and LDHA (11-14). We recently revealed that stable HIF-1 $\alpha$ knockdown attenuated the hypoxic induction of Warburg effect-related genes, and induced apoptosis owing to excessive ROS production in 58As9 cells (41). In the present study, we also noted that transient HIF-1 $\alpha$ knockdown decreased cell survival under hypoxia in the three GC cell lines (data not shown). Therefore, HIF-1 $\alpha$ activation under hypoxia may form a feedback loop for controlling ROS generation and cell survival in GC cells. Based on the above findings, the mtROS/ HIF-1 $\alpha$ interplay may be activated in 44As3 and 58As9 cells, because these two cell lines possess both high mtROS production and HIF-1 $\alpha$ overexpression. As a result, 44As3 and $58 \mathrm{As} 9$ cells with HIF-1 $\alpha$ overexpression may accelerate cancer aggressiveness by more strongly upregulating expression of genes related to cell survival and invasion under hypoxia, in comparison to MKN45 with the lower activity of the mtROS/ HIF-1 $\alpha$ interplay.

To address further mechanisms underlying the activation of the mtROS/HIF-1 $\alpha$ interplay, we focused on mitophagy, which is essential in mitochondrial quality control, and hypothesized that the mitophagy process might be impaired, whereby the mitochondria damaged by mtROS could not be eliminated in hypoxic 44As3 and 58As9 cells. We first analyzed the expressions of LC3-I/II and p62, which are recognized as general autophagy markers (28). Western blot analysis revealed that the LC3-I/II ratio as well as p62 expression was not altered in 44As3 and 58As9 cells under hypoxic conditions. In sharp contrast, a decreased LC3-I/II ratio and loss of p62 were observed in hypoxic MKN45 cells in a time-dependent manner. These results indicated that autophagy was induced in MKN45 cells but not in 44As3 or 58As9 cells under hypoxia. Fluorescence microscopy demonstrated that the staining of LC3B-RFP was strongly increased by hypoxia in MKN45 cells, but not in the other two cell lines. The co-localization of LC3B-RFP and Mitotracker suggested hypoxia-induced mitophagy in MKN45 cells. We further investigated the lysosomal digestion targeting the mitochondria by assessing autolysosome formation. The results showed that the co-localization of Mitotracker and Lysotracker was observed only in hypoxic MKN45 cells, and confirmed that the entire process of mitophagy is intact in MKN45 cells under hypoxia. The mtROS production by hypoxic stimulation might be controlled at a low level through the normal mitophagy process in MKN45 cells. In contrast, mtROS might be accumulated 
under hypoxia in 44As3 and 58As9 cells owing to impaired mitophagy. The increased mtROS might subsequently inhibit the activity of PHDs, followed by enhanced HIF-1 $\alpha$ stability. As a result, the induced HIF-1 $\alpha$ might facilitate the aggressive characteristics in these two cell lines under hypoxia. To confirm the mtROS/HIF-1 $\alpha$-induced cancer aggressiveness following impaired mitophagy, we finally investigated whether the autophagy inhibitor CQ disturbed the mitophagy process in hypoxic MKN45 cells and increased cancer aggressiveness. The results showed that the normal autophagy process was inhibited in hypoxic MKN45 cells with CQ treatment. Moreover, HIF-1 $\alpha$ expression as well as mtROS production was elevated under hypoxic conditions in the CQ-treated cells. $\mathrm{CQ}$ treatment also increased the cell survival and invasion ability in MKN45 cells under hypoxia. These results indicated that the artificial impairment of mitophagy might also increase cancer aggressiveness via activating the mtROS/HIF-1 $\alpha$ interplay in MKN45 cells. Fig. 7 summarizes a novel mechanism of hypoxia-induced cancer aggressiveness that originates from the impairment of mitophagy in GC cells.

In conclusion, the present study demonstrated for the first time that the integrity of mitophagy determined the cancer aggressiveness of GC cells under hypoxia via the activation of the mtROS/HIF- $1 \alpha$ interplay. Isolation of abnormality of expression of genes encoding regular autophagy factors or mitophagy specific factors might be important for more precise understanding of this novel theory.

\section{Acknowledgements}

This study was supported by JSPS KAKENHI Grants-in-Aid for Scientific Research on Scientific Research (Research Project no. 15K10103) (to J.N.).

\section{References}

1. Torre LA, Bray F, Siegel RL, Ferlay J, Lortet-Tieulent J and Jemal A: Global cancer statistics, 2012. CA Cancer J Clin 65 87-108, 2015.

2. Shiraishi N, Inomata M, Osawa N, Yasuda K, Adachi Y and Kitano S: Early and late recurrence after gastrectomy for gastric carcinoma. Univariate and multivariate analyses. Cancer 89 : 255-261, 2000.

3. Macdonald JS, Smalley SR, Benedetti J, Hundahl SA, Estes NC, Stemmermann GN, Haller DG, Ajani JA, Gunderson LL, Jessup JM, et al: Chemoradiotherapy after surgery compared with surgery alone for adenocarcinoma of the stomach or gastroesophageal junction. N Engl J Med 345: 725-730, 2001.

4. Iyer NV, Kotch LE, Agani F, Leung SW, Laughner E, Wenger RH, Gassmann M, Gearhart JD, Lawler AM, Yu AY, et al: Cellular and developmental control of $\mathrm{O}_{2}$ homeostasis by hypoxia-inducible factor 1 alpha. Genes Dev 12: 149-162, 1998.

5. Harris AL: Hypoxia - a key regulatory factor in tumour growth. Nat Rev Cancer 2: 38-47, 2002.

6. Vaupel P, Mayer A and Höckel M: Tumor hypoxia and malignant progression. Methods Enzymol 381: 335-354, 2004.

7. Lu X and Kang Y: Hypoxia and hypoxia-inducible factors: Master regulators of metastasis. Clin Cancer Res 16: 5928-5935, 2010.

8. Höckel M and Vaupel P: Tumor hypoxia: Definitions and current clinical, biologic, and molecular aspects. J Natl Cancer Inst 93 266-276, 2001.

9. Jiang BH, Semenza GL, Bauer C and Marti HH: Hypoxiainducible factor 1 levels vary exponentially over a physiologically relevant range of $\mathrm{O}_{2}$ tension. Am J Physiol 271: C1172-C1180 1996.

10. Semenza GL: Defining the role of hypoxia-inducible factor 1 in cancer biology and therapeutics. Oncogene 29: 625-634, 2010.
11. Semenza GL: Targeting HIF-1 for cancer therapy. Nat Rev Cancer 3: 721-732, 2003.

12. Semenza GL: HIF-1 and tumor progression: Pathophysiology and therapeutics. Trends Mol Med 8 (Suppl): S62-S67, 2002.

13. Semenza GL: HIF-1: Upstream and downstream of cancer metabolism. Curr Opin Genet Dev 20: 51-56, 2010.

14. Kitajima Y and Miyazaki K: The critical impact of HIF-1 $\alpha$ on gastric cancer biology. Cancers (Basel) 5: 15-26, 2013.

15. Ide T, Kitajima Y, Miyoshi A, Ohtsuka T, Mitsuno M, Ohtaka K, Koga Y and Miyazaki K: Tumor-stromal cell interaction under hypoxia increases the invasiveness of pancreatic cancer cells through the hepatocyte growth factor/c-Met pathway. Int J Cancer 119: 2750-2759, 2006

16. Sumiyoshi Y, Kakeji Y, Egashira A, Mizokami K, Orita H and Maehara Y: Overexpression of hypoxia-inducible factor 1alpha and p53 is a marker for an unfavorable prognosis in gastric cancer. Clin Cancer Res 12: 5112-5117, 2006.

17. Nam SY, Ko YS, Jung J, Yoon J, Kim YH, Choi YJ, Park JW, Chang MS, Kim WH and Lee BL: A hypoxia-dependent upregulation of hypoxia-inducible factor- 1 by nuclear factor- $x \mathrm{~B}$ promotes gastric tumour growth and angiogenesis. Br J Cancer 104: 166-174, 2011.

18. Stoeltzing O, McCarty MF, Wey JS, Fan F, Liu W, Belcheva A, Bucana CD, Semenza GL and Ellis LM: Role of hypoxia-inducible factor lalpha in gastric cancer cell growth, angiogenesis, and vessel maturation. J Natl Cancer Inst 96: 946-956, 2004.

19. Nakamura J, Kitajima Y, Kai K, Hashiguchi K, Hiraki M, Noshiro H and Miyazaki K: HIF-1alpha is an unfavorable determinant of relapse in gastric cancer patients who underwent curative surgery followed by adjuvant 5 -FU chemotherapy. Int $\mathbf{J}$ Cancer 127: 1158-1171, 2010.

20. Rohwer $\mathrm{N}$ and Cramer T: HIFs as central regulators of gastric cancer pathogenesis. Cancer Biol Ther 10: 383-385, 2010.

21. Sena LA and Chandel NS: Physiological roles of mitochondrial reactive oxygen species. Mol Cell 48: 158-167, 2012.

22. Zepeda AB, Pessoa A Jr, Castillo RL, Figueroa CA, Pulgar VM and Farías JG: Cellular and molecular mechanisms in the hypoxic tissue: Role of HIF-1 and ROS. Cell Biochem Funct 31: 451-459, 2013.

23. Chandel NS, McClintock DS, Feliciano CE, Wood TM, Melendez JA, Rodriguez AM and Schumacker PT: Reactive oxygen species generated at mitochondrial complex III stabilize hypoxia-inducible factor-1alpha during hypoxia: A mechanism of $\mathrm{O}_{2}$ sensing. J Biol Chem 275: 25130-25138, 2000.

24. Gerald D, Berra E, Frapart YM, Chan DA, Giaccia AJ, Mansuy D, Pouysségur J, Yaniv M and Mechta-Grigoriou F: JunD reduces tumor angiogenesis by protecting cells from oxidative stress. Cell 118: 781-794, 2004

25. Zhao T, Zhu Y, Morinibu A, Kobayashi M, Shinomiya K, Itasaka S, Yoshimura M, Guo G, Hiraoka M and Harada $H$ : HIF-1-mediated metabolic reprogramming reduces ROS levels and facilitates the metastatic colonization of cancers in lungs. Sci Rep 4: 3793, 2014.

26. Kaelin WG Jr: ROS: Really involved in oxygen sensing. Cell Metab 1: 357-358, 2005.

27. Semenza GL: Hypoxia-inducible factor 1: Regulator of mitochondrial metabolism and mediator of ischemic preconditioning. Biochim Biophys Acta 1813: 1263-1268, 2011.

28. Mizushima N, Yoshimori T and Levine B: Methods in mammalian autophagy research. Cell 140: 313-326, 2010.

29. Mathew R, Karantza-Wadsworth V and White E: Role of autophagy in cancer. Nat Rev Cancer 7: 961-967, 2007.

30. Mizushima N and Komatsu M: Autophagy: Renovation of cells and tissues. Cell 147: 728-741, 2011.

31. Rogov V, Dötsch V, Johansen T and Kirkin V: Interactions between autophagy receptors and ubiquitin-like proteins form the molecular basis for selective autophagy. Mol Cell 53: 167-178, 2014.

32. Lemasters JJ: Selective mitochondrial autophagy, or mitophagy, as a targeted defense against oxidative stress, mitochondrial dysfunction, and aging. Rejuvenation Res 8: 3-5, 2005.

33. Kim I, Rodriguez-Enriquez S and Lemasters JJ: Selective degradation of mitochondria by mitophagy. Arch Biochem Biophys 462: 245-253, 2007.

34. Chourasia AH, Boland ML and Macleod KF: Mitophagy and cancer. Cancer Metab 3: 4, 2015.

35. Liu L, Feng D, Chen G, Chen M, Zheng Q, Song P, Ma Q, Zhu C, Wang R, Qi W, et al: Mitochondrial outer-membrane protein FUNDC1 mediates hypoxia-induced mitophagy in mammalian cells. Nat Cell Biol 14: 177-185, 2012. 
36. Zhang H, Bosch-Marce M, Shimoda LA, Tan YS, Baek JH, Wesley JB, Gonzalez FJ and Semenza GL: Mitochondrial autophagy is an HIF-1-dependent adaptive metabolic response to hypoxia. J Biol Chem 283: 10892-10903, 2008.

37. Cesari R, Martin ES, Calin GA, Pentimalli F, Bichi R, McAdams H, Trapasso F, Drusco A, Shimizu M, Masciullo V, et al: Parkin, a gene implicated in autosomal recessive juvenile parkinsonism, is a candidate tumor suppressor gene on chromosome 6q25-q27. Proc Natl Acad Sci USA 100: 5956-5961, 2003.

38. Gong Y, Zack TI, Morris LG, Lin K, Hukkelhoven E, Raheja R, Tan IL, Turcan S, Veeriah S, Meng S, et al: Pan-cancer genetic analysis identifies PARK2 as a master regulator of G1/S cyclins. Nat Genet 46: 588-594, 2014

39. Yanagihara K, Takigahira M, Tanaka H, Komatsu T, Fukumoto $H$ Koizumi F, Nishio K, Ochiya T, Ino Y and Hirohashi S: Development and biological analysis of peritoneal metastasis mouse models for human scirrhous stomach cancer. Cancer Sci 96: 323-332, 2005.
40. Miyake S, Kitajima Y, Nakamura J, Kai K, Yanagihara K, Tanaka T, Hiraki M, Miyazaki K and Noshiro H: HIF-1 $\alpha$ is a crucial factor in the development of peritoneal dissemination via natural metastatic routes in scirrhous gastric cancer. Int J Oncol 43: 1431-1440, 2013

41. Tanaka T, Kitajima Y, Miyake S, Yanagihara K, Hara H, Nishijima-Matsunobu A, Baba K, Shida M, Wakiyama K, Nakamura J, et al: The apoptotic effect of HIF-1 $\alpha$ inhibition combined with glucose plus insulin treatment on gastric cancer under hypoxic conditions. PLoS One 10: e0137257, 2015.

42. Dolman NJ, Chambers KM, Mandavilli B, Batchelor RH and Janes MS: Tools and techniques to measure mitophagy using fluorescence microscopy. Autophagy 9: 1653-1662, 2013. 